\title{
Decreased Level of Vitamin D is Associated with Rheumatoid Arthritis Patients from Western Region of Nepal
}

\author{
Tamrakar BK ${ }^{1 *}$, Karki $\mathbf{D}^{1,2}$, Nagila $\mathrm{A}^{3}$ \\ 'Department of Internal Medicine, Fishtail Hospital \& Research centre, Pokhara, Nepal \\ ${ }^{2}$ Department of Internal Medicine, Manipal College of Medical Sciences, Pokhara, Nepal \\ ${ }^{3}$ Department of Laboratory, Fishtail Laboratory, Gairapatan, Pokhara, Nepal
}

\section{Keywords}

Anti-CCP, RA Factor,

Rheumatoid arthritis, Vitamin D.

\section{Corresponding author}

"Dr. Basant kumar Tamrakar

Consultant Physician

Department of Internal Medicine, Fishtail Hospital \& Research centre, Pokhara, Nepal Email: basant.k.tamrakar@gmail.com

\section{ABSTRACT}

Background: Rheumatoid Arthritis (RA) is a progressive, chronic type of autoimmune disease and the role of vitamin $D$ in the pathogenesis of RA is under investigation.

Objective: The objective of this study was to determine the vitamin D deficiency in patients with RA as compared to healthy controls and to assess the relationship between serum vitamin $\mathrm{D}$ and anti-cyclic citrullinated peptide (anti-CCP) antibody levels in patients with newly diagnosed rheumatoid arthritis.

Methods: The study was conducted between January 2017 to February 2018 at Fishtail Hospital and Research centre. A total of 63 patients with early RA diagnosed and a control group of 56 healthy participants, not on vitamin D supplements were recruited from Department of Internal Medicine. Five ml of blood samples were drawn from cubital veins. Blood glucose, creatinine, uric acid, calcium, RA factor, 25-hydroxy vitamin D, anti-CCP antibody, and erythrocyte sedimentation rates were measured in a centralized laboratory of Fishtail Hospital and Research centre.

Results: The level of serum 25-hydroxy vitamin D were significantly lower in RA group (20.03 $\pm 9.97 \mathrm{ng} / \mathrm{mL}$ ) in comparison to the control group $(24.46 \pm 8.45 \mathrm{ng} / \mathrm{mL}) \quad(\mathrm{p}<0.003)$. Our result indicates the prevalence of vitamin D deficiency was more in RA group compared with control group ( $47.61 \%$ vs. $33.16 \%, p<0.002$ ). The level of AntiCCP is significantly high in RA group than control group. In RA patients serum 25-hydroxy vitamin $D$ levels were negatively correlated to antiCCP antibody levels ( $\mathrm{rs}=0.72, \mathrm{p}<0.001)$, and erythrocyte sedimentation rate ( $\mathrm{rs}=3.95, \mathrm{p}<0.005)$.

Conclusion: In RA patient vitamin D deficiency is quite common and serum 25-hydroxy vitamin D level was negatively correlated to anti-CCP antibody level. Our results suggest that vitamin D level is a motivation factor rather than a consequence of RA activity.

\section{INTRODUCTION}

Rheumatoid Arthritis (RA) is a progressive, chronic type of autoimmune disease characterized by joint pain, stiffness in hands, feet and other parts of the body ${ }^{1}$. Worldwide prevalence of RA is one percent which has been found to be more common in females than in males. The patients with RA shows the symptoms of morning stiffness, joint 
pain, swelling, anemia, loss of appetite and weight loss. Its pathogenesis is still under investigation, although the role of genetic susceptibility, environmental factors, and immune activation is indispensable ${ }^{1,2,3,4}$. However, in more severe case it can cause irreversible damage of joints and can also cause damage in other body organs such as eyes, lungs, blood vessels and skin. Therefore, biomarkers are required for early diagnosis to prevent the damage. RA factor and anti-cyclic citrullinated peptide (antiCCP) antibody are most commonly used biomarkers to diagnose RA. But anti-CCP antibody has been found to be more specific for RA than RA factor ${ }^{5}$. Anti-CCP antibodies, auto-antibodies found in sera of RA patients has been found to be more reliable than RA factor for diagnosing rheumatoid arthritis which is detectable in very early stage of the disease ${ }^{6}$. Early diagnosis may help to prevent the irreversible damage of joints ${ }^{7,8}$.

Vitamin D, also known as secosteroid is a fat-soluble hormone, which can be generated following ultraviolet light irradiation of the skin and plays vital role in metabolism of bone and calcium. Furthermore, it also plays role in modulation of cell growth, neuromuscular and immune function, and reduction of inflammation. 25-hydroxy vitamin D deficiency is linked to rickets among children and osteomalacia and osteoporosis among adults9. Deficiency of vitamin D is involved in the pathogenesis of RA, as well as activity of RA. The decrease of vitamin D is related to older age, female gender and a higher degree of RA activity ${ }^{10,11}$. Hilger J et al. reported that prevalence of vitamin D level in the context of Asia/Pacific region is significantly lower level ${ }^{12}$. Song et al. found that in a meta-analysis, involvement of vitamin $D$ at the onset of $\mathrm{RA}^{10}$. They found that individuals with the highest level of vitamin D intake from food had a $24 \%$ lower risk of developing RA than those in the lowest group. However, in another study vitamin $D$ intake was not associated with the risk of $\mathrm{RA}^{13}$. Thus, present study aimed to determine the level of 25-hydroxy vitamin D in RA patients and assess the relationship between serum vitamin D and anti-CCP antibody levels in patients with newly diagnosed RA.

\section{METHODS}

The study subjects of 63 RA patients (29 males and 34 females) were recruited in between January 2017 to February 2018, from the Internal Medicine Department, Fishtail Hospital and Research Centre, Pokhara, Nepal.
Newly diagnosed RA patients with disease duration of less than one year and had not been treated with non-steroidal anti-inflammatory drugs. All enrolled patients fulfilled the American college of Rheumatology or European league against rheumatism RA classification criteria. Apparently 56 healthy individuals ( 26 males and 30 females) of the region having either no health problem or not receiving any therapeutic treatment were used as the normal control group. All the subjects in RA group and control group were consented by the Institutional Review Board of the Hospital to participate in the study. At the time of sample collection information regarding demography, lifestyle and health/medical history was recorded in the predesigned questionnaire.

The following blood tests were evaluated in the blood serum at the Department of Laboratory of Fishtail Hospital and Research Centre. Blood sample were drawn aseptically from cubital vein. A total of $5.0 \mathrm{ml}$ of venous blood was drawn from each subject. Blood samples were allocated in plane tube and EDTA tube. EDTA blood used for erythrocyte sedimentation rates (ESR) by automated machine, sedy- 12 ESR analyzer, unique diagnostics. Clotted bloods allocated in plane tube were then centrifuged at $2000 \mathrm{rpm}$ for 10 minutes to separate serum samples and glucose, creatinine, uric acid, and calcium were measured using standard protocol in both RA and control group by fully automated biochemistry analyzer. RF test, 25-hydroxy vitamin D, and anti-CCP antibody were measured in serum sample of RA group, however, only serum 25-hydroxy vitamin D levels were measured in the control group. Qualitative RF in serum was determined by latex agglutination method (Medsource Ozone Biomedicals). Serum 25-hydroxy vitamin D levels and Anti-CCP levels were measured by an automated electrochemiluminescent immunoassay from Siemens Immunoassay system. Vitamin D status was defined as follows: $\geq 30 \mathrm{ng} / \mathrm{mL}$, sufficiency; $<29 \mathrm{ng} / \mathrm{mL}$, $\geq 21 \mathrm{ng} / \mathrm{mL}$, insufficiency; $\leq 20 \mathrm{ng} / \mathrm{mL}$, deficiency and for anti-CCP testing, a level of $\geq 25$ relative units $\mathrm{IU} / \mathrm{mL}$ was considered positive ${ }^{14,15}$.

\section{Statistical analysis}

The statistical analysis was under taken using SPSS version 20.0 software. Quantitative data were expressed as mean \pm SD. Student t-test was used to compare quantitative data of two groups. Chi square test was applied for qualitative data analysis and one way ANOVA was used to compare the differences between different sub groups. The level 
of significance was considered when $\mathrm{p}$ value $<0.05$ was considered as cut off value for significance.

\section{RESULTS}

Total of 63 RA patients fulfilled the American college of Rheumatology or European league against rheumatism RA classification criteria and age, sex matched 56 healthy control groups was included in the study. Out of 63 RA patients, males were 29 (46\%) and females were 34 (54\%), whereas, in control group 26 (41\%) males and 30 (48\%) were females. The comparison of anthropometric parameters age, SBP, DBP, BMI, Waist/Hip ratio are summarized in Table 1 . The mean age of the RA patient $52.8 \pm 13.6$ and control group $49.7 \pm 11.9$ showed a nonsignificant difference $(\mathrm{P}=0.09)$. Systolic blood pressure (SBP) and diastolic blood pressure (DBS) was noted statistically non significant between RA and control group. The mean of both BMI and waist hip ration was noted statistically non significant in between two groups.

Table 1: Anthropometric parameters of fatty liver and healthy control persons

\begin{tabular}{lccc}
\hline Parameters & $\begin{array}{c}\text { RA groupMean } \\
\mathbf{\pm S D}(\mathbf{n}-63)\end{array}$ & $\begin{array}{c}\text { Control group } \\
\text { Mean } \pm \text { SD } \\
(\mathbf{n}-\mathbf{5 6})\end{array}$ & P-value \\
Age & $52.8 \pm 13.6$ & $49.7 \pm 11.9$ & NS \\
Systolic & $123.7 \pm 14.9$ & $126.9 \pm 12.4$ & NS \\
Diastolic & $88.2 \pm 7.5$ & $87.5 \pm 10.1$ & NS \\
Height & $165.5 \pm 8.7$ & $166.5 \pm 7.7$ & NS \\
Weight & $73.4 \pm 11.5$ & $72.6 \pm 9.2$ & NS \\
BMI & $26.3 \pm 3.5$ & $25.7 \pm 4.7$ & NS \\
Waist/Hip ratio & $0.93 \pm 0.1$ & $0.91 \pm 0.1$ & NS \\
\hline
\end{tabular}

NS=Non-significant, SD = Standard deviation, $\mathrm{p}$ value $<0.05$ is considered significant

Comparison of serum biochemical profiles means between RA group and control group are shown in Table 2. Fasting blood sugar (FBS), HbA1C, creatinine, AST and ALT were compared in between RA and control group, and result shows there were no statistically difference between these groups. Serum uric acid level were not higher than normal range in both RA and control groups, however, there was significantly higherlevel of uric acid in RAgroup than control group (5.63 \pm 0.81 Vs $4.28 \pm 0.59, \mathrm{P}=0.04)$. Interestingly, ESR is higher in RA group in comparison to the control group (24.35 \pm 11.26 Vs $9.71 \pm 7.09, \mathrm{P}=0.001)$. Moreover, Anti-CCP antibody was significantly increased in RA group (37.4 \pm 26.3$)$ than control group $(17.7 \pm 12.8)$, giving $p$ value 0.02 . Interestingly, the mean of 25-hydroxyvitamin D concentration in RA group (20.0 \pm 9.7$)$ is significantly lower than control group $(24.4 \pm 8.5)(\mathrm{P}=0.003)$. The vitamin $\mathrm{D}$ level in males and females were calculated. In both RA and control group the mean level of vitamin D is not different by sex (Table 3). Interestingly, vitamin D deficiency was more prevalent in RA group compared with control group (47.61\% vs. 33.16\%, p=0.002) (Table 3). In RA group, correlation coefficients of different variables with serum vitamin D level were presented in Table 4 . Multiple linear regression tests indicates that there is an inverse relationship between serum 25 hydroxyvitamin D and Anti-CCP antibody ( $\mathrm{p}=0.002)$.

Table 2: Biochemical parameters of rheumatoid arthritis (RA) group and control group

\begin{tabular}{lccc}
\hline Parameters & $\begin{array}{c}\text { RA group } \\
\text { Mean } \pm \text { SD } \\
\text { (n-63) }\end{array}$ & $\begin{array}{c}\text { Control group } \\
\text { Mean } \pm \text { SD } \\
\text { (n-56) }\end{array}$ & P-value \\
Glucose & $98.18 \pm 13.60$ & $96.40 \pm 10.38$ & NS \\
HbA1C & $5.72 \pm 0.78$ & $5.61 \pm 0.59$ & NS \\
Creatinine & $1.13 \pm 0.19$ & $1.07 \pm 0.18$ & NS \\
Uric Acid & $5.63 \pm 0.81$ & $4.28 \pm 0.59$ & 0.04 \\
AST & $32.51 \pm 14.26$ & $31.26 \pm 10.58$ & NS \\
ALT & $30.06 \pm 12.57$ & $29.41 \pm 13.70$ & NS \\
$\begin{array}{l}\text { ESR (mm/1 } \\
\text { hr) }\end{array}$ & $24.35 \pm 11.26$ & $9.71 \pm 7.09$ & 0.001 \\
$\begin{array}{l}\text { Anti-CCP anti- } \\
\text { body (IU/ml) }\end{array}$ & $35.4 \pm 26.37$ & $17.7 \pm 12.83$ & 0.02 \\
$\begin{array}{l}\text { 25-hydroxyvita- } \\
\text { min D(ng/mL) }\end{array}$ & $20.03 \pm 9.97$ & $24.46 \pm 8.45$ & 0.003 \\
\hline
\end{tabular}

$\mathrm{SD}=$ Standard deviation, $\mathrm{NS}=$ Non significant, $\mathrm{p}$ value $<0.05$ is considered significant. AST = Aspartate transaminase, ALT = Alanine aminotransferase, ESR = Erythrocyte sedimentation rate, Anti-CCP antibody = Anti cyclic citrullinated peptide antibody

Table 3: The level of 25-hydroxyvitamin D in RA group and Control group

\begin{tabular}{lccc}
\hline Parameters & $\begin{array}{c}\text { RA group Mean } \\
\mathbf{\pm S D}\end{array}$ & $\begin{array}{c}\text { Control group } \\
\text { Mean } \pm \text { SD }\end{array}$ & P-value \\
$\begin{array}{l}\text { 25-hydroxyvitamin } \\
\text { D (In males) }\end{array}$ & $20.17 \pm 9.23$ & $25.75 \pm 8.92$ & 0.001 \\
$\begin{array}{l}\text { 25-hydroxyvitamin } \\
\text { D (In females) }\end{array}$ & $19.91 \pm 10.25$ & $23.17 \pm 7.97$ & 0.001 \\
$\begin{array}{l}\text { 25-hydroxyvitamin } \\
\text { D Deficiency ratio }\end{array}$ & 47.61 & 33.16 & 0.002 \\
$\begin{array}{l}\text { 25-hydroxyvitamin } \\
\text { D Insufficiency ratio }\end{array}$ & 34.92 & 46.48 & 0.01 \\
$\begin{array}{l}\text { 25-hydroxyvitamin } \\
\text { D Sufficiency ratio }\end{array}$ & 17.46 & 20.36 & 0.09 \\
\hline SD = Standard deviation, p value $<0.05$ is considered
\end{tabular}


significant

Table 4: The correlation coefficient of different variables with serum 25-hydroxyvitamin D levels within rheumatoid arthritis (RA) group

\begin{tabular}{cccc}
\hline Variables & Mean \pm SD & $\begin{array}{c}\text { Estimated } \\
\text { coefficient }\end{array}$ & P-value \\
Age (years) & $52.8 \pm 13.6$ & -0.61 & 0.001 \\
Gender & - & 0.17 & 0.38 \\
$\begin{array}{c}\text { ESR }\left(\mathrm{mm} / 1^{\text {st }}\right. \\
\mathrm{hr})\end{array}$ & $24.35 \pm 11.26$ & -3.95 & 0.005 \\
$\begin{array}{c}\text { Anti-CCP anti- } \\
\text { body (IU/ml) }\end{array}$ & $35.4 \pm 26.37$ & -0.72 & 0.001 \\
\hline
\end{tabular}

$\mathrm{SD}=$ Standard deviation, NS = Non significant, $\mathrm{p}$ value $<0.05$ is considered significant. ESR = Erythrocyte sedimentation rate, Anti-CCP antibody = Anti cyclic citrullinated peptide antibody.

\section{DISCUSSION}

The comparison of anthropometric parameters age, SBP, DBP, BMI, waist/hip ratio are not statistically significant in between RA and control group suggesting that these parameters are not associated with rheumatoid arthritis. There was significantly higher level of uric acid in RA group than control group $(5.63 \pm 0.81$ Vs $4.28 \pm 0.59, \mathrm{P}=0.04)$ suggested that uric acid play a role in the pathogenesis of arthritis. Anti-CCP antibody, are used as highly sensitive marker in the diagnosis and severity evaluation of RA. In the present study, we found that increased anti-CCP and decreased ESR in RA than control are accepted results.

We have found that vitamin $\mathrm{D}$ deficiency (25-hydroxyvitamin D) values $<20 \mathrm{ng} / \mathrm{mL}$ is common in RA patients affecting $47 \%$ of the entire cohort. Our results are similar to various report presented in smaller sizes, with a prevalence of vitamin $\mathrm{D}$ deficiency ranging from $30-63 \% 16,17,18$. In the present study 25 -hydroxyvitamin D levels were in insufficiency level (24.46 \pm 8.45$)$ even in control groups, suggesting that the level of vitamin D is slightly lower in Nepalese population, which may be due to food and personal behavior. Also the normal ranges of vitamin D we use are acquired from Western counties. Our results shows significant decrease of vitamin D in RA than control group, confirms the correlation between rheumatoid arthritis and vitamin D. We suggest that vitamin D may play the crucial role in the formation of arthritis and recent studies have highlighted on the immunological activity of vitamin $\mathrm{D}$, which is independent of its classical role in the regulation of calcium ${ }^{19}$.

We demonstrated negatively correlated serum 25-hydroxyvitamin D levels to the anti-CCP antibody levels. Anti-CCP antibody, early marker of RA can be used as an indicator for supplementation treatment of vitamin $\mathrm{D}$ in the early rheumatoid arthritis patients. However, anti-CCP antibodies were shown to have no correlation with serum 25-hydroxyvitamin D in chronic RA patients ${ }^{20}$. In our study, we have enrolled the first diagnose early RA patients and our results are as similar to the recent work, where serum 25-hydroxyvitamin D levels were reduced in patients with RA and negatively associated with disease activity $^{21}$. Moreover, intake of vitamin D can lower the risk of $\mathrm{RA}^{10}$.

\section{CONCLUSION}

In RA patient vitamin $\mathrm{D}$ deficiency is quite common and serum 25-OH-D level was negatively correlated to antiCCP antibody level. Our results suggest that vitamin D level is a motivation factor rather than a consequence of RA activity. Further studies on the role of vitamin D in the pathogenesis of RA are required.

\section{REFERENCES}

1. Lee DM, Weinblatt ME. Rheumatoid arthritis. Lancet. 2001; 38: 125-39.

2. Andersson AK, Li C, Brennan FM. Recent developments in the immunobiology of rheumatoid arthritis. Arthritis Research \& Therapy. 2008; 10(2): 204.

3. Atzeni F, Talotta R, Masala IF, Bongiovanni S, Boccassini L, Sarzi-Puttini P. Biomarkers in Rheumatoid Arthritis. The Israel Medical Association Journal (IMAJ). 2017; 19(8): 512-6.

4. van Venrooij WJ, van Beers JJ, Pruijn GJ. AntiCCP Antibody, a Marker for the early detection of rheumatoid arthritis. Annals of the New York Academy of Sciences. 2008; 1143: 268-85.

5. Niewold TB, Harrison MJ, Paget SA. Anti-CCP antibody testing as a diagnostic and prognostic tool in rheumatoid arthritis. QJM: Monthly Journal 
of the Association of Physicians. 2007; 100 (4): 193201.

6. van der Woude D, Catrina AI. HLA and anticitrullinated protein antibodies: Building blocks in RA. Best practice \& research Clinical rheumatology. 2015; 29(6): 692-705.

7. Imboden JB. The Immunopathogenesis of rheumatoid arthritis. Annual Review of Pathology: Mechanisms of Disease. 2009; 4(1): 417-34.

8. Sokolove J, Johnson DS, Lahey LJ, Wagner CA, Cheng D, Thiele GM, et al. Rheumatoid factor as a potentiator of anti-citrullinated protein antibodymediated inflammation in rheumatoid arthritis. Arthritis \& Rheumatology (Hoboken, NJ). 2014; 66(4): 813-21.

9. Wang Y, Zhamg F, Wang S, Shang X et al. Serum vitamins $\mathrm{D}$ level is inversely associated with anticyclic citrullinated peptide antibody level and disease activity in rheumatoid arthritis patients. Arch Rheumatol. 2016; 31(1): 64-70.

10. Song GG, Bae SC, Lee YH. Association between vitamin $\mathrm{D}$ intake and the risk of rheumatoid arthritis: A meta-analysis. Clin Rheumatol. 2012; 31: 1733-9.

11. Kim TH, Choi SJ, Lee YH, Song GG, Ji JD. Combined therapeutic application of mTOR inhibitor and vitamin $\mathrm{D}(3)$ for inflammatory bone destruction of rheumatoid arthritis. Med Hypotheses. 2012; 79: 757-60.

12. Hilger J, Friedel A, Herr R, Rausch T, Roos F, Wahl $\mathrm{DA}$, et al. A systematic review of vitamin D status in populations worldwide. The British Journal of Nutrition. 2014; 111(1): 23-45.

13. Baker JF, Baker DG, Toedter G, Shults J, Von Feldt JM, Leonard MB. Associations between vitamin D, disease activity, and clinical response to therapy in rheumatoid arthritis. Clin Exp Rheumatol. 2012; 30: 658-64.

14. Dawson-Hughes B, Heaney RP, Holick MF, Lips P, Meunier PJ, Vieth R. Estimates of optimal vitamin D status. Osteoporos Int. 2005; 16: 713-6.

15. Souberbielle JC, Body JJ, Lappe JM, Plebani M, Shoenfeld Y, Wang TJ, et al. Vitamin D and musculoskeletal health, cardiovascular disease, autoimmunity and cancer: Recommendations for clinical practice. Autoimmun Rev. 2010; 9: 709-15.

16. Aguado P, del Campo MT, Garces MV, GonzalezCasaus ML, Bernad M, Gijon-Banos J, Martín Mola E, Torrijos A, Martínez ME: Low vitamin D levels in outpatient postmenopausal women from a rheumatology clinic in Madrid, Spain: their relationship with bone mineral density. Osteoporos Int. 2000; 11: 739-744.

17. Solomon DH, Finkelstein JS, Shadick N, LeBoff MS, Winalski CS, Stedman M, Glass R, Brookhart MA, Weinblatt ME, Gravallese EM: The relationship between focal erosions and generalized osteoporosis in postmenopausal women with rheumatoid arthritis. Arthritis Rheum. 2009, 60: 1624-1631.

18. Craig SM, Yu F, Curtis JR, Conn DL, Jonas B, Callahan LF, Smith EA, Moreland LW, Bridges SL Jr, Mikuls TR: Vitamin D status and its associations with disease activity and severity in African Americans with recent-onset rheumatoid arthritis. J Rheumatol. 2010; 37: 275-281.

19. Zwerina K, Baum W, Axmann R, Heiland GR, Distler $\mathrm{JH}$, Smolen J, et al. Vitamin D receptor regulates TNF-mediated arthritis. Ann Rheum Dis. 2011; 70: 1122-9.

20. Sahebari M, Mirfeizi Z, Rezaieyazdi Z, Rafatpanah H, Goshyeshi L. 25(OH) vitamin D serum values and rheumatoid arthritis disease activity (DA S28 ESR). Caspian J Intern Med. 2014; 5: 148-55.

21. Hong Q, Xu J, Xu S, Lian L, Zhang M, Ding C. Associations between serum 25-hydroxyvitamin D and disease activity, inflammatory cytokines and bone loss in patients with rheumatoid arthritis. Rheumatology (Oxford) 2014; 53: 1994-2001. 